\title{
IT SOLUTIONS, PLC.: INTRODUCING A BIG DATA CASE INTO THE ACCOUNTING CURRICULUM
}

\author{
Eleonora Stancheva-Todorova ${ }^{1}$, Mirella Dimitrova ${ }^{2}$
}

\begin{abstract}
By bridging the accounting and data science domains, this paper introduces an interdisciplinary Big Data case study for accounting students that implements a specific methodology framework. It is supported by clear learning objectives and detailed instructor's implementation guidance that complement a fascinating scenario, representing a real-world situation in the data-led world of business. The participants' assignment is to propose a strategy for improving financial position and performance of a particular company by attracting new customers selected among companies, listed on the London Stock Exchange. The data sources of the proposed case study are publicly available and comprise of historical financial and nonfinancial data, disclosed in companies' annual reports. By performing their assigned roles under the case study scenario, future graduates will build upon their technological competences as well as raise their awareness on the new roles and job tasks of the future accountant. They will also gain understanding on the new advisory function of the accounting specialists and their responsibilities as management consultants in the data-let business world. From a research perspective, this interdisciplinary work demonstrates how expertise in text mining and financial reporting might be combined for revealing new investment opportunities and enhancing management decisions.
\end{abstract}

JEL Classification Numbers: M41, C55, DOI: https://doi.org/10.12955/peb.v2.259

Keywords: big data, accounting, case study, interdisciplinary

\section{Introduction}

In a data-driven business environment, accounting professionals should be well equipped with the needed skills and competences to benefit from current and emerging technology advances that inevitably change the accounting ecosystem and trigger accounting evolutions into new dimensions. Accounting educators play an important role in this process as they have to prepare future graduates for their new role and functions within organization boundaries. They are challenged to develop comprehensive study materials and implement successful approaches for infusing Big Data and data analytics into the accounting coursework.

This paper introduces an interdisciplinary Big Data case study for accounting students that applies a specific methodology framework. Our goal is to develop a comprehensive teaching material that might be integrated into an accounting module. It is supported by well-defined assignment tasks, proper methodology and clear learning objectives that complement a fascinating scenario, representing a realworld situation in the data-led world of business. This interdisciplinary case study bridges the accounting and data science domains. From an instructor's perspective, it might be considered as a useful supplement to the accounting and financial reporting study materials and an illustration of how data analytical tools could be applied for supporting management decision-making. Moreover, it demonstrates how the usefulness of a company's financial statements is expanded by deploying data analytics techniques. In addition, the case study could be easily replicated or modified and adapted to any educational environment due to the provided teaching guidance and case extensions.

From the students' perspective, our target is to help them develop some of the knowledge and competences required by employers from accounting graduates. As these skills and abilities comprise the skill set of the future accountant, expertise in Big Data and data analytics could help them to better perform their job tasks in a "digital enterprise" (PWC, 2016) and embrace the opportunities of new technologies and their augmented application.

\section{Literature review}

In 1989, the largest accounting and auditing firms published a joined document criticizing the current approach for teaching accounting at universities that, in their opinion, was designed in a lecture/problem style and was textbook-oriented. They were also calling for fundamental changes in the curriculum by introducing a more creative use of information technology to enhance the capabilities of accounting students and prepare them for the technology-driven era of business (Black, 2012; Stancheva-Todorova, 2019a; 2019b). Since then, the Big 4 companies are one of the driving factors for the evolution of

\footnotetext{
${ }^{1}$ Sofia University "St. Kliment Ohridski”, Faculty of Economics and Business Administration, Department of Finance and Accounting, Bulgaria, e_stancheva@feb.uni-sofia.bg

${ }^{2}$ Sofia University "St. Kliment Ohridski", Faculty of Economics and Business Administration, Bulgaria, dimitrovamirella@gmail.com, (part-time lecturer)
} 
accounting higher education. An evidence for their significant contribution in this process are their profound surveys and other publications on the development trend of the accounting profession driven by new disruptive technologies (EY, 2014; PWC, 2015; 2016; KPMG, 2016). Professional accounting bodies also play an important role in reshaping the global educational landscape by their professional standards. As a response to the increased digitalization of global business, the Association of Chartered Certified Accountants, the Institute of Chartered Accountants in England and Wales and the Chartered Global Management Accountants started to modify some of their qualification modules by infusing information technologies into the syllabi (Bennett, 2019; Gamage, 2016). The American Accounting Association (AAA), in collaboration with the American Institute of Certified Public Accountants (AICPA), created the US Pathways Commission on Accounting Higher Education to develop a national strategy and direct the future of accounting higher education in the country (Behn et al., 2012). According to the Commission's study, published in 2015, business analytics is considered one of the most important competencies for students (AAA \& AICPA, 2015). The Association to Advanced Collegiate Schools of Business (AACSB) is also an advocate of incorporating data analytics learning objectives into accounting curriculum and manifested it in its accreditation Standard A5 Information Technology Skills, Agility and Knowledge for Accounting Graduates and Faculty (AACSB, 2018).

Implementation of Big Data analytics into the accounting coursework is still a challenging issue for educators despite the huge body of supporting teaching materials developed and collected over the last decade. Their in-class use depends on the implementation approach, applied by the accounting faculty. Gamage (2016) outlines a list of Big Data topics that can be included within existing courses. This discipline-based approach is in line with the publication of Sledgianowski et al. (2017), who built it upon and propose few curriculum integration methods. The co-authors demonstrate and provide guidance on how data analytics might be embedded into several modules such as Financial Accounting, Management and cost accounting, Auditing, Accounting information systems and Taxation. In their seminal paper, Dzuranin et al. (2018) go further by identifying three methods for infusing data analytics into the accounting coursework - a focused approach, an integrative approach and a hybrid approach. Moreover, in their broad exploratory survey, the authors provide empirical results indicating which data analytical skills and competences should be developed in accounting students, where in the curriculum, how, and when they should be taught. The work of Enget et al. (2017) also contribute to this challenging educational issue. The researchers develop a case study, aiming to help future accountants to gain understanding of Big Data and AISPA's AU Section 316, Consideration of Fraud in a Financial Statement Audit within the context of the journal entry test work as well as to supplement students' analytical skill set.

\section{Case description and requirements}

\section{Company Background}

IT Solutions is a UK-based public limited company that provides cybersecurity, cloud and artificial intelligence services and currently transforms the business of more than 800 customers in 20 European countries. The organization is an employer of 200 people operating in six different departments Administration, Finance, Sales and marketing, Procurement, Research and development and Services delivery. The Finance department comprises of specialists in accounting, financial planning and analysis, and business intelligence. It runs its business centrally from their headquarters, located in London. The company is in the IT business for more than two decades. However, in the last few years it reports a quarterly year-on-year decline in revenues. The senior management of the Sales and Marketing department is looking for an opportunity to increase the sales volume and improve the company's financial position and performance. He initiated a data-driven project with collaboration from the Finance department to support the sales specialists in attracting new clients.

\section{Students' Role and Task Assignments}

Assume you are an accountant at IT Solutions plc. You are assigned to join this cross-functional team with the job task to create an automated model for identifying prospective clients to support the company's sales department. After a brainstorming session, the group decides to explore annual reports of the UK public companies listed on the London Stock Exchange and identify firms that might benefit from security services, cost optimization through cloud services or that are planning to go through digital transformations. Some predefined data from companies' financial statements will be extracted for 
assessing their financial position and performance - an important point of information for every potential business partner. The members of the join-team should complete five tasks. First, they must download the annual reports in .pdf format for randomly selected companies listed on the London Stock Exchange. Their second task is to identify key words related to IT Solutions' business and outline potential problem areas for the selected companies. Next, students should create a matrix showing how often, in which annual reports and in what context each key word can be found. The fourth task implies development of an algorithm to extract key financial indicators from the annual reports and store them in a database. Finally, they analyze the results and make recommendations to the sales managers for prospective clients of IT Solutions plc. The students should complete the first two tasks outside of class by working in groups, each comprising of three to five people. All other tasks will be performed in-class under the guidance of the instructor.

\section{Case Study Data Sources and Methodology Framework}

Accounting students will use annual reports of UK public companies as a primary source of historic data for this case study. A comprehensive list of all companies listed on the London Stock Exchange is provided on: https://www.londonstockexchange.com/reports?tab=issuesrs. Participants are encouraged to choose companies classified as part of the Main Market. Organizations from the Financial Services sector as well as those that are incorporated in countries other than United Kingdom are excluded for simplicity. The annual reports are usually published on the companies' official websites. Moreover, the annual reports of a great variety of public companies are available at: https://www.annualreports.com/.

The students have to process a large amount of information to complete the assigned tasks. They have to explore a whole host of .pdf files, each comprising of 50 to 200 pages. Hence, an automated algorithm for data extraction and key word searching has to be developed. A powerful tool for text mining that is at the heart of the IT Solutions case study, is the R programming language. In the specific case of working with .pdfs, a useful R library is "pdftools". One of the most commonly used techniques that are applied when working with unstructured text data are punctuation, stop words and unnecessary white spaces removal, tokenization and normalization. Deployment of these tools will contribute to completing the in-class work assignment. Furthermore, in terms of data cleaning and processing, the knowledge on regular expressions will be put into practice - in $\mathrm{R}$ this can be achieved via a few libraries such as "tm", "stringr", etc.

\section{Teaching notes}

\section{Curriculum integration approach}

According to the provided evidence in the profound survey of Dzuranin et al. (2018), the hybrid approach for incorporating Big Data and data analytics into the accounting curriculum is supported by the majority of the faculty. This method implies implementation of data analytics in almost every accounting module parallel to a stand-alone specialized module in Big Data. Interestingly, the survey's findings indicate that the accounting department should be responsible for providing data analytics education to accounting students though many respondents support the collaborative work of both the accounting department and the information systems department. Insights from faculty also reveal that data analytics content might be implemented into the Financial reporting course though it was not listed on the first few places in the predefined course list. Furthermore, the results show data analytics topics should be taught only by faculty with sufficient training in the field.

The proposed case study is in line with Dzuranin et al.'s (2018) findings. Based on our academic experience, we are proponents of the hybrid method and strongly agree that some data analytics teaching content might be properly infused into accounting courses that are supported by well-trained accounting faculty. The IT Solutions plc. case study is inspired by a real-world situation and has already been integrated into the Advanced financial accounting and reporting module for master students. Its syllabus and teaching content are developed by a team of academics, comprising of two full-time professors one in accounting and one in data science and a part-time lecturer with business experience in financial planning and analysis, gained in a big international IT company. By combining the expertise of the team's members, a substantial synergetic effect from the educational perspective has been achieved. By completing this module and as a result of the accomplished interdisciplinary learning objectives, students' financial accounting and reporting competences will be complemented with the required technological skills and abilities. 
Alternatively, this hypothetical case study might be implemented in an accounting information systems course or in a separate data analytics course for accounting students depending on the master program's curriculum as it offers teaching material applicable in a different educational environment. We also support the arguments provided by Stancheva-Todorova \& Bogdanova (2020), that pedagogical opportunities also exist for incorporating teaching materials on emerging technologies and their application into other modules, for instance into the Corporate finance or Financial statement analysis. Furthermore, the proposed case study might be embedded into non-accounting modules such as an advanced module in Business analytics and further developed in a machine learning course due to its interdisciplinary methodological framework and comprehensible business scenario though some case study modifications might be relevant.

The educational background of the accounting students participating in this interdisciplinary case study should be consistent with the targeted learning objectives and applicable data analytical and software tools. Their profound knowledge in financial accounting and reporting is essential for extracting the key financial indicators from listed companies' annual reports. Moreover, the completion of the fourth task requires students to be familiar with the regulatory framework. Hence, they should be able to identify specific accounting policies, developed under the International Financial Reporting Standards and their implications on companies' financial data. Furthermore, students need to gain advance knowledge in business analytics and statistics and develop some basic skills in programming in R. They should be able to work with data frames, create loops and extract specific data elements using regular expressions.

\section{Learning objectives}

After completing the aforelisted assignment tasks, participants in this hypothetical case will accomplish four learning objectives that are in line with the needed skills and competences, required from accounting graduates in a data-led business environment. The first leaning objective for students is to understand how Big Data and data analytics can be used for solving a variety of accounting issues. Next, they will gain some practical experience on the application of specific data analytical tools. Identification of opportunities for improving management decisions by enhancing the usefulness of companies annul reports refers to the third learning objective. Finally, participants should comprehend the new consultancy role of the accountants within the organization and their involvement in strategic decision making.

The learning methods, implemented into the case study materials, are relevant to the targeted learning outcomes and support their achievement. Accounting students have an intermediary level opportunity to utilize Big Data analytical tools for automated data extraction from companies' annual reports provided in .pdf format, data retrieval and pre-processing for the purpose of calculating specific financial indicators. Moreover, they are involved in experiential learning as they imitate the job task performance of business experts engaged in assessing the financial position and performance of a company's potential clients to support management decisions. Furthermore, future accountants improve their software skills through the use of specific database software as they utilize R tools for accomplishing the case study learning objectives. In addition, by participating in the IT Solutions plc. case study, students develop their analytical and communication competences as well as a higher order thinking skillset.

\section{Task implementation guidance}

The accounting students will be split into groups. As part of their self-study they should select between 50 and 100 companies listed on the London Stock Exchange. The latter will be used for testing the developed model for data extraction and analysis. Participants might be provided with a couple of "hints and tips" to support them in the selection process. For example, they could be advised to choose only companies categorized as part of the Main Market as we consider it as an indicator for the high quality of the published reports (London Stock Exchange, 2020). Furthermore, students are encouraged not to exclude banks, insurance companies and other financial institutions from the samples despite the fact that their financial reporting is usually under specific regulations. Selecting companies from a variety of industries guarantees that the sample is representative.

After completing the selection, the students have to download the annual reports, including financial statements, that are publicly available only in .pdf format. To support management decision making by identifying trends of development, problem areas and potentials for digital transformation of processes and business activities, the explored historical financial information should be at least for a 5-year 
period. As this might be a time-consuming task, participants are advised to further split into subgroups to work out jointly this part of the assignment.

After downloading the .pdf files, the accounting students are challenged to approach the problem from a business perspective. The key for attracting new clients to IT Solutions plc. is to identify new business opportunities for the selected prospective customers and work proactively towards approaching them with congruent technical solutions that might optimize their business processes and improve their competitiveness. As the processing of a large amount of text data is a time-consuming task, the students need to create, as part of their home assignment, a list of key words related to the technical products and services provided by the company. Examples of such words and phrases are "cloud", "security", "cybersecurity", "artificial intelligence", "cost saving", "optimization", etc. Next, the participants in this case study should develop, in-class, a model that identifies companies for further and more profound review that might benefit from IT Solutions plc. business products, based on the frequency and context of appearance of the selected words and phrases. For achieving comprehensive results after completing the second and the third task, students should be advised by the instructor to use synonyms and abbreviations of the key words to "catch" more of their appearances in the annual reports.

The third task might be split into three subtasks. First, the students need to create a vector of all selected phrases. Then, the vector will be used to scan through the unstructured text data of the annual reports and next, by using the keyword_search function in R, to obtain information about the context and the exact place where each keyword appears. The students will be provided with explanation of how the function works and how it can be applied in R studio as illustrated in Figure 1.

\begin{tabular}{|l|}
\hline Figure 1: Keyword_search function in R \\
\hline $\begin{array}{r}\text { AnnualReportcompanyx <- keyword_search ("CompanyXannualReport2018.pdf", keyword }=\text { keyword, path }=\mathrm{T}, \\
\text { ignore_case }=\mathrm{T} \text {, convert_sentence }=\mathrm{F} \text { ) }\end{array}$ \\
\hline Source: Authors
\end{tabular}

As a final step in completing task three, the participants in the IT Solutions plc. case study have to create a matrix showing how often, in which annual reports and in what context each key word can be found. The output hint is provided in Figure 2.

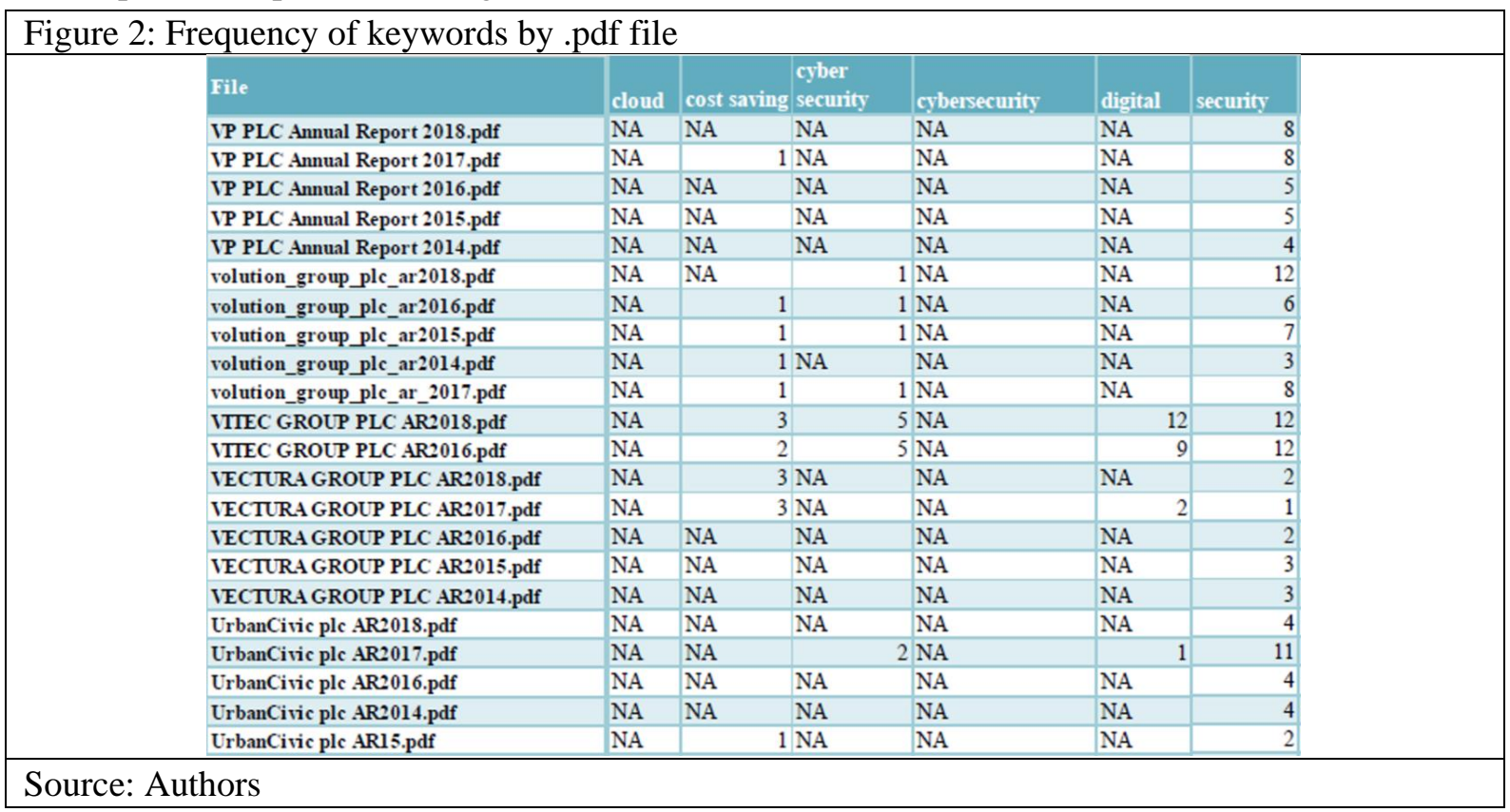

Accounting students should be able to identify and suggest companies for further review with the option to recreate the output matrix, or perform a more focused and detailed analyses of the company's annual report to reveal new business opportunities for IT Solutions plc.

The last in-class assignment requires the extraction and pre-processing of accounting data for further and more in-depth analysis to support management decision making. Therefore, under the assistance of the instructor, the future accounting graduates should apply their knowledge in creating loops and work 
with regular expressions. The suggested algorithm for data extraction first requires students to find the page of the financial statement, then to look for the currency sign, and finally to extract the currency. The next two steps are to find the row of the accounting indicator, and to find and extract the value. Then, they have to insert the value in a data frame. Finally, they have to delete the file and continue to the next one.

As the participants process a huge amount of unstructured data, the sufficient computing power and competent and timely software assistance are important factors for the successful completion of this interdisciplinary case study and the instructor plays an important role in providing technical support to the participants. According to Lewis and Young (2019), the median number of words in the annual reports has increased from 14,954 to 33,193 for the period between 2003 and 2016.

For optimizing the performance of the workstation and achieving targeted results, students will use a loop to apply the algorithm on one file, extract the desired information and add it to a data frame and then remove it and proceed with the next one. Once the annual report is loaded in R, the text is split by pages and considered as its elements. Further, by creating and using a vector comprising of a consequence of keywords, students will find the page of the financial statement component. For example, for finding the income statement page, the words "income", "statement", "ended", "revenue", "profit" should be placed and identified in one single element of the report. As a company's financial results might be expressed in different currencies which complicates their comparative analysis, the currency sign should be detected and indicated in the data frame. As a result, further adjustments and analysis of the data might be performed. By applying the next step of the suggested algorithm, the row containing the specific accounting indicator, that is in the focus of the case study - for example "operating profit" (we assume that the word appears only once on the page), is identified. Different terms might be used in a company's annual reports as "operating profit", "profit from operations", "operating profit/loss" or "operating profit (loss)". Hence, accounting students should consider as many synonyms and combinations of terms as possible to successfully complete this assignment task. Next, by using regular expressions, the row should be split into separate elements for indicating the current period value based on its position. If the required information cannot be found, the number of the page with more details might be specified. The expected output matrix of the applied algorithm is presented in Figure 3.

\begin{tabular}{|c|c|c|c|c|c|c|}
\hline File & Currency & Revenue & Gross profit & Operating profit & Profit before tax & Net profit \\
\hline 4IMPRINT GROUP PLC AR2014.pdf & USD & $415,773,000$ & check page 46 & $24,142,000$ & check page 46 & check page 46 \\
\hline 4IMPRINT GROUP PLC AR2015.pdf & USD & $497,219,000$ & check page 50 & $31,963,000$ & $31,157,000$ & $22,695,000$ \\
\hline 4IMPRINT GROUP PLC AR2016.pdf & USD & $558,223,000$ & check page 48 & $34,696,000$ & $34,151,000$ & $24,479,000$ \\
\hline 4IMPRINT GROUP PLC AR2017.pdf & USD & $627,518,000$ & check page 57 & $41,284,000$ & $40,659,000$ & $28,925,000$ \\
\hline 4IMPRINT GROUP PLC AR2018.pdf & USD & $738,418,000$ & check page 60 & $44,322,000$ & $44,146,000$ & $35,194,000$ \\
\hline AA PLC Annual Report 2015.pdf & GBP & $983,500,000$ & $638,100,000$ & check page 80 & $60,800,000$ & $69,100,000$ \\
\hline AA PLC Annual Report 2016.pdf & GBP & $973,000,000$ & $626,000,000$ & check page 92 & $17,000,000$ & $6,000,000$ \\
\hline AA PLC Annual Report 2017.pdf & GBP & check page 90 & $592,000,000$ & check page 90 & $100,000,000$ & $154,000,000$ \\
\hline AA PLC Annual Report 2018.pdf & GBP & check page 103 & $600,000,000$ & check page 103 & $141,000,000$ & $111,000,000$ \\
\hline Aptitude Software AR2014.pdf & GBP & $29,814,000$ & check page 48 & $6,161,000$ & $5,766,000$ & $4,113,000$ \\
\hline Aptitude Software AR2015.pdf & GBP & $31,958,000$ & check page 53 & $5,273,000$ & $4,885,000$ & $3,734,000$ \\
\hline Aptitude Software AR2016.pdf & GBP & $42,988,000$ & check page 60 & $8,212,000$ & $7,881,000$ & $6,243,000$ \\
\hline
\end{tabular}

As part of their homework assignment, the accounting students should make the necessary adjustments in terms of missing data and figures expressed in different currencies and continue with the financial analysis. This is the final step for identifying prospective clients of IT Solutions plc. As the in-class assignments focus on companies' income statement, accounting students might apply a similar algorithm for data extraction from the balance sheets (statements of financial position) and utilize the information for the purposes of the last case study task. They could be advised by the instructor to focus on indicators related to the organization's debt and liquidity and assess them from the creditor's perspective.

\section{Conclusion}

The proposed interdisciplinary case study might be used for infusing Big data and data analytics into the accounting curriculum. It might be extended in terms of both text mining and financial statement analysis. One possibility is to enhance the analysis of unstructured data. The dataset might be expanded 
by adding in text from preliminary earnings announcements, news, and social media posts. This might reveal an opportunity to identify and analyze their tone as well as the tone in the annual reports and specifically in the Chairman's statement. Another option for the extension of the case study is to implement a method for assessing a stock's market value through fundamental analysis. For the quantitative evaluation, accounting students might use text mining techniques to conclude on a variety of important issues such as a company's image, strategy and executives, the risks it is exposed to in the current and future periods, etc. by analyzing the frequency of certain key words and phrases and the tone of the annual reports or specific sections only.

\section{References}

Behn, B. K., Ezzell, W. F., Murphy, L. A., Rayburn, J. D., Stith, M. T., \& Strawser, J. R. (2012). The Pathways Commission: Charting a National Strategy for the Next Generation of Accountants. Issues in Accounting Education, 27(3): 595-600. https://doi.org/10.2308/iace-10300

AAA \& AICPA. (2015). The Pathways Commission: In Pursuit of Accounting's Curricula of the Future. Retrieved from http://commons.aaahq.org/groups/0fa82ab56d/summary

AACSB. (2018). Standard A5: Information Technology Skills, Agility and Knowledge for Accounting Graduates and Faculty. Eligibility Procedures and Accreditation Standards for Accounting Accreditation. Retrieved from https://tinyurl.com/5e75fvdu

Bennett, J. (2019, April 1). A data analytics unit is being added to ACCA's Ethics and Professional Skills module to help members stay ahead of the curve. ACCA. Retrieved from https://www.accaglobal.com/gb/en/cam/power-of/ab/dataanalytics.html

Black, W. H. (2012). The Activities of the Pathways Commission and the Historical Context for Changes in Accounting Education. Issues in Accounting Education, 27 (3), 601-625. https://doi.org/10.2308/iace-50091

Dzuranin, A. C,, Jones, J. R., \& Olvera, R. M. (2018). Infusing data analytics into the accounting curriculum: A framework and insights from faculty. Journal of Accounting Education, 43, 24-39. https://doi.org/10.1016/j.jaccedu.2018.03.004

Enget, K., Saucedo, G. D., \& Wright, N. S. (2017). Mystery, Inc.: A Big Data case. Journal of Accounting Education, 38, 922. https://doi.org/10.1016/j.jaccedu.2016.12.003

EY. (2014). Big data changing the way businesses compete and operate, Retrieved from https://dl.icdst.org/pdfs/files2/8e7f03e2a5c148145615328ec03b2e33.pdf

Gamage, P. (2016). Big Data: are accounting educators ready?. Accounting and Management Information Systems, 15(3), 588-604.

KPMG. (2016). The Factory of the Future. Industry 4.0 - The Challenges of tomorrow. Retrieved from https://assets.kpmg/content/dam/kpmg/pdf/2016/05/factory-future-industry-4.0.pdf

Lewis, C. \& Young, S. (2019). Fad or future? Automated analysis of financial text and its implications for corporate reporting. Accounting and Business Research, 49, 587-615. https://doi.org/10.1080/00014788.2019.1611730

London Stock Exchange. (2020). Main Market. Retrieved from https://www.londonstockexchange.com/raisefinance/equity/main-market

PWC. (2015, February). Data driven. What students need to succeed in a rapidly changing business world. Retrieved from https://www.pwc.com/us/en/faculty-resource/assets/pwc-data-driven-paper-feb2015.pdf

PWC. (2016). Industry 4.0: Building the digital enterprise. Retrieved from https://www.pwc.com/gx/en/industries/industries4.0/landing-page/industry-4.0-building-your-digital-enterprise-april-2016.pdf

Sledgianowski, D., Gomaa, M \& Tan, Ch. (2017). Toward integration of Big Data, technology and information systems competencies into accounting curriculum. Journal of Accounting Education, 38, 81-93.

https://doi.org/10.1016/j.jaccedu.2016.12.008

Stancheva-Todorova, E. P. \& Bogdanova, B. (2021). Enhancing investors' decision-making - an interdisciplinary AI-based case study for accounting students. AIP Conference Proceedings 2333, 150007 (2021). https://doi.org/10.1063/5.0041612

Stancheva-Todorova, E. P. (2019a). Accounting educators and practitioners on alert - the time for bigger and constant changes has come. Accounting, Audit and Finance in the Changing World Conference Proceedings. University of Economics - Varna, 92-106. Retrieved from https://www.ceeol.com/search/chapter-detail?id=787277

Stancheva-Todorova, E.P. (2019b). Integrating Big data analytics competence into the accounting curriculum. Contemporary Management Practices X. Connectivity and Regional Partnerships Conference Proceedings. Burgas Free University, 170177. Retrieved from https://www.ceeol.com/search/article-detail id $=820351$ 